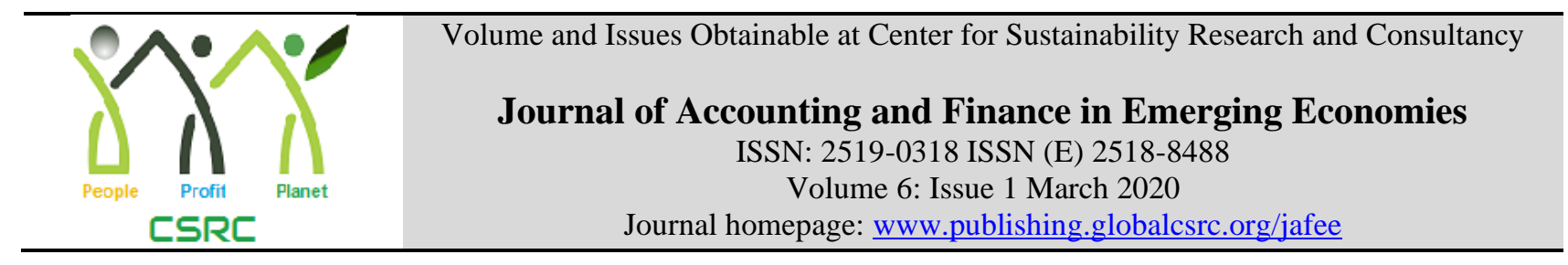

\title{
What motivates and deters the 'crowd' in crowdfunding in Malaysia?
}

\author{
${ }^{1}$ Shaista Wasiuzzaman, ${ }^{2}$ Hemalatha A/P Pannir Chelvam
}

${ }^{1}$ Senior Lecturer, Faculty of Management, Multimedia University, Malaysia: shaista@mmu.edu.my

${ }^{2}$ MPhil student, Faculty of Management, Multimedia University, Malaysia: herishnavibala95@ gmail.com

\begin{tabular}{l} 
ARTICLE DETAILS \\
\hline History \\
Revised format: February 2020 \\
Available Online: March 2020 \\
\\
Keywords \\
Crowdfunding, Perceived Values, \\
Perceived Risk, Small And \\
Medium Enterprises (Smes), \\
Malaysia
\end{tabular}

JEL Classification:

G29, A13, A19

\begin{abstract}
Objective: This study intends to theorize about how values and the perception of risk of the supporters of a crowdfunding project affect the success of the project.

Methodology: A review of prior literature is carried out to identify the different dimensions of the decision making process.

Implication: This research presents a conceptual framework to describe the influence of perceived values and risk on the success of crowdfunding in Malaysia. The crowdfunding phenomenon is relatively new in Malaysia and there is a lack of knowledge about the decision making of the 'crowd'. The success and sustainability of the crowdfunding phenomenon depends on the supporters of the funds.
\end{abstract}

\section{OPEN ACCESS}

(C) 2020 The authors, under a Creative Commons Attribution-Non

Commercial 4.0

Corresponding author's email address: shaista@mmu.edu.my

Recommended citation: Wasiuzzaman, S., Chelvam, H. A/P. P., (2020). What motivates and deters the 'crowd' in crowdfunding in Malaysia? Journal of Accounting and Finance in Emerging Economies, 6 (1), 323-330

DOI: $10.26710 /$ jafee.v6i1.1095

\section{Introduction}

Entrepreneurship plays a big role in economic growth as it reduces poverty through wealth creation, innovation and technology deployment. It has been found that countries experience higher economic growth when there is a focus on entrepreneurship and self-employment (Soete and Stephen, 2004). It is essential to maintain and propagate a country's competitiveness especially with the increasing trend of globalization (Venkatachalam and Waqif, 2005). Identifying entrepreneurship as one of the key drivers of Malaysia's progression, the Malaysian government introduced several initiatives in its 2015 budget, where several perks were introduced to start and support entrepreneurial ventures and to boost research and development. In its 2016 budget, RM100 million was allocated to Agensi Inovasi Malaysia (AIM) and an automatic double reduction of RM50,000 in R\&D expenses for SMEs to encourage the entrepreneurial spirit in Malaysia (http://www.nst.com.my/news/2015/10/2016-budget-encouragesentrepreneurship-and-innovation). Based on a statistical report from the Malaysia Labor Force Survey in 2014, the number of entrepreneurs has shown a marginal increase between 1982 and 2012. During this period, the number of entrepreneurs increased from 1.3 million to 2.6 million, respectively. 
Despite the various initiatives introduced by the Malaysian government, according to a census conducted by the Department of Statistics Malaysia, SMEs prime source of financing has been their own funds or internally generated funds which includes borrowing from friends and family. Only about $20 \%$ financing comes from financial institutions and government loans due to the various constraints faced, such as lack of collateral, insufficient documents and no financial track record to support loan application, etc. However, with the increasing number of web-based platforms, entrepreneurs are able to reach investors on a wider scale. One major financing source is crowdfunding. In recognition of the importance of ECF (equity crowdfunding) as an alternative early-stage financing avenue, Malaysia was the first country in ASEAN to introduce a regulatory framework to facilitate equity crowdfunding in 2015 , whereby it made amendments to its Capital Markets and Services Bill (CMSB). 6 registered equity crowdfunding operators were licensed in June 2015 and were fully operational by 2016. Unlike Singapore where only accredited and institutional investors are allowed to participate in securities-based funding, in Malaysia, the ECF is an investment product made available to, not just registered angel investors and sophisticated investors, but also to retail investors. However, various regulations have been set to protect the investors, especially the unsophisticated ones. Despite these measures, there are still risks involved in ECF since it is a new social phenomenon and information about it is still limited. These risks and other social, emotional and other factors may affect the decision making process of the crowdfunder hence affecting the success of a crowdfunding project. However, literature on this is still quite limited and therefore, this study aims to understand the motivations and deterrents for participation in crowdfunding projects.

Given the current financial landscape for entrepreneurs in Malaysia, in order to ensure that entrepreneurial ventures achieve success, it is very important that greater effort is put into implementing the right assistance so that the companies can grow and their contribution to the country's economy is boosted. Currently, first-time entrepreneurs are unable to acquire adequate assistance hence they are unable to tap into their potential. Although the Malaysian government has devised various initiatives to provide financial assistance to entrepreneurs, the initiatives are not able to fulfill the entrepreneurs' financial requirements, especially in the case of start-up ventures. Crowdfunding is touted to be one of the possible solutions to the financing gap but the success of any crowdfunding project depends on the funding it receives from its supporters/investors and it is therefore important to understand what motivates and deters these supporters/investors from investing in any project. This research is thus aimed at providing further insight into the crowdfunding phenomenon in Malaysia and the community supporting this phenomenon in order to ensure sustained participation in this new and rapidly growing phenomenon.

\section{Literature Review}

Bank lending to SMEs in Asia has been found to be very low according to studies conducted by the Asian Development Bank. The study finds that in almost all South East Asian (SEA) economies, only 18.7\% of total bank lending were to SMEs. Post the global financial crisis of 2009, bank lending to SMEs has seen a downward trend. Aside from bank lending, other external financing options available to SMEs and entrepreneurs are venture capital (VC) and angel investors. However, according to David Rose of Rose Tech Ventures, the chances of securing funding from these sources are especially slim as VCs typically invest in about $0.25 \%$ of the companies they evaluate whilst angel investors in about $2.5 \%$ of the companies they evaluate. Around 9 million SMEs in Asia do not have sufficient access to financing and this lack of financing inhibits their growth. Entrepreneurs face many obstacles in raising finance due to limited business operating history and the riskiness of the business, which is a result of their ideas being too innovative or complex, especially during the start-up phase of their business. Therefore, they mostly rely on friends, family and fools (Kotha and George, 2012) for their financing.

Crowdfunding is defined as "an open call, mostly through the internet, for the provision of financial resources either in the form of donation or in exchange for the future product or some form or reward and/or voting rights" (Belleflamme et al, 2014). Crowdfunding is growing rapidly around the world. In year 2014, one of the biggest platforms in the world, kickstarter.com, collected $\$ 529$ million single- 
handedly through funds raised from a large number of people who contributed relatively small amounts. There were more than 700 crowdfunding platforms around the world in 2012 and this number has increased to more than 1250 online crowdfunding platforms in 2015, with an estimated over 2000 platforms by early 2016 given the trend. Crowdexpert.com estimated the total fundraising volume in 2015 to be approximately $\$ 34$ billion, out of which $\$ 5.5$ billion was raised via reward and donation crowdfunding and $\$ 2.5$ via equity crowdfunding. Of the $\$ 34$ billion, $\$ 10.54$ billion was raised in Asia and crowexpert.com estimates the growth in crowdfunding in Asia to be approximately $210 \%$, the highest for any region in the world. The total transaction value in the reward-based crowdfunding segment amounts to $\$ 2.8$ billion in 2017 in Asia and an approximately 31.2\% annual growth is estimated until year 2021. For the case of Malaysia, the transaction value amounts to US $\$ 0.5$ million with growth estimated to be $15.4 \%$ by year 2021. However, according to the Asian Institute of Finance (2017) report, the only $10 \%$ of the public has invested in crowdfunding in year 2015 and $70 \%$ of the public were only willing to spend RM100 per project. To ensure the growth and sustainability of the crowdfunding phenomenon, it is essential to understand the psychology and the decision making process of the investors in crowdfunding, also known as the 'crowd'.

Despite the growing popularity of crowdfunding, little scholarly research can be found in this domain. Crowdfunding avoids some of the barriers that can impede offline financial transactions and enables the dissemination of product information, increase consumer awareness, and estimate consumer willingness to pay (Belleflamme et al., 2010). Prior studies have investigated the link between motivations and contributions to online communities (Kraut and Resnick, 2012) but only few scholars have investigated the motivations for crowdfunding through online platforms. Studies examining the crowdfunding phenomenon (Belleflamme et al, 2010; Kraut and Resnick, 2012; Schwienbacher and Larralde, 2012; Kuppuswamy and Bayus, 2015; Xu et al, 2014) assert that crowdfunding needs to be sustainable in order to grow and benefit a larger group of entrepreneurs. The success of the phenomenon depends on the supporters of the funds, i.e. the crowd. Investor are purported to be rational decision makers but prior studies have found that investors allow their emotions and mind to influence their investment decisions (Kraut and Resnick, 2012).

In a case study of a company that raised money using crowdfunding techniques, Schwienbacher and Larralde (2012) found that supporters were motivated to participate in the project because of the excitement and the adventure related to building a startup and so that they could expand their network with other supporters. Most crowdfunding platforms facilitate interactivity between project initiators and crowdfunders by allowing crowdfunders to comment on, 'like', rank, or even report a project. In order to increase their likelihood of success, project creators or initiators are able to take advantage of this interactivity by communicating through project actions such as providing videos and posting project updates (Mollick, 2014). Kuppuswamy and Bayus (2015) and Xu et al. (2014) find that the number of project updates posted by a fund-seeker posts has a positive impact on the project's campaign success while Verheart and Van den Poel (2012) find that the chance of success is higher if project's creator or initiator announce the amount of seed fund raised during the funding process. There is also evidence of a herd effect in crowdfunding. Accordingly, Lin et al. (2013) fund that information of prior contribution and other crowfunders' choices influence a project's success.

In consumer behavior literature, decision making is considered from several perspectives - the 'information processing perspective', the 'affective perspective', and the 'value perspective' (Moysidou and Spaeth, 2016). From the information processing perspective (Bettman, 1979), consumers decision making requires them to solve problems rationally through logical thinking (Blackwell et al., 2001). However, according to the affective perspective, consumer decision making is very much affected by their affections and emotional responses. The value perspective provides a more holistic approach to consumer decision making. According to this perspective, consumers are "value driven" (Holbrook, 1996). 
According to Sheth et al. (1991), five value factors contribute to consumer decision making - functional value, social value, emotional value, epistemic value and conditional value. Functional value refers to "whether or not a product is able to perform its attribute-related, utilitarian, or physical purposes" while social value reflects the "social and symbolic benefits offered by a product" (Moysidou and Spaeth, 2016, pg. 4). Emotional value reflects the experiental or emotional benefits derived from a product while epistemic value is caused by a desire for knowledge which may be due to intellectual curiosity or noveltyseeking objectives. Conditional value is based on situations or the circumstances that a consumer faces which influences his/her decision to either purchase the product or not (Moysidou and Spaeth, 2016). Prior research has identified two generic dimensions which incorporate various perceived values such as quality of product, quality of service, emotional and social value (Roig et al., 2006). The two generic dimensions that these values fall under are the cognitive value dimension and the affection value dimension (Roig et al., 2006). The cognitive value refers to the rational and economic assessment of a problem and therefore includes the value of the product and service quality while the affective dimension is focused on the feeling or emotions generated from using a product and/or service and this dimension includes the social and emotional values attached to a product and/or service.

The main reason why entrepreneurs and small and medium enterprises (SMEs) face difficulty in securing funds from financial institutions is their opaque nature. Their opaque nature is a result of their poor record keeping and insufficient documentation. The high levels of information asymmetry makes it difficult for banks and non-bank financial institutions to assess their credit risk. Crowdfunding is based on social capital and according to Agarwal et al. (2015), social capital is able to reduce perceived information asymmetry, hence the uncertainty associated with investing in entrepreneurial activities, and is perceived as a sign of credibility. Therefore, increased availability of information improves credibility and reduces information asymmetry and this reduces the risk related to a crowdfunding project hence improving the success of the project. However, crowdfunding as an investment option has its risks. Companies seeking funds through crowdfunding are usually high-risk companies and are not required to provide financial or operational data since they are unlisted companies (Turan, 2015). The companies may not be audited properly and there may not be enough information for investors to compare with to make their decisions. The crowdfunder/investor also faces the risk of losing all the invested capital as there is a high probability for start-ups and early businesses to fail. In terms of dividends, the companies being growth companies would prefer reinvest the profits for growth and to build value and hence may not pay dividends for many years. Additionally, since there is no secondary market for the investments, it may be difficult or even impossible to sell the investment in the future. Even if the investor does not wish to sell the investment, there is the risk of dilution of the shares of the investor if the company decides to raise more capital in the future (Turan, 2015).

This study therefore focuses on the decision making process of the crowdfunder via these two dimensions, i.e. the cognitive and affective dimensions. It also considers the risk associated with a crowdfunding project which has been found to influence the decision to support a project. Based on the discussions above, the following propositions are put forward:

P1: The cognitive dimension will influence the crowdfunder's decision to support a project.

P2: The affection dimension will influence the crowdfunder's decision to support a project.

P3: Perceived risk of the project or the crowdfunding platform will influence the crowdfunder's decision to support a project. 


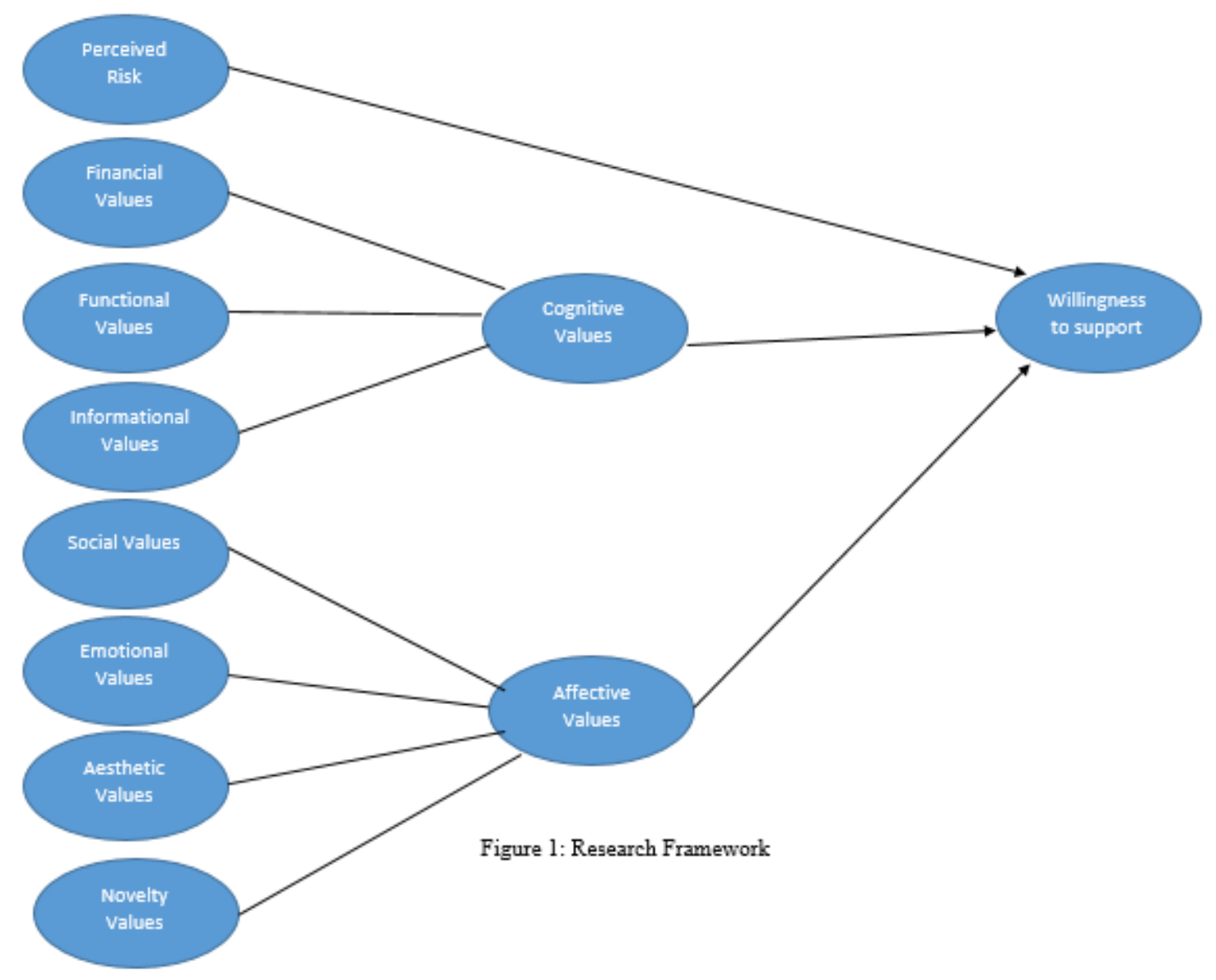

Figure 1: Presents the Research Framework

\section{Methodology}

To achieve the objectives of this study, a survey questionnaire will be developed and distributed. Since this study is about crowdfunder's (or supporter's) decision making, the respondents will be those who have or are considering supporting request for funds on a crowdfunding platform hence the research uses purposive sampling method. There are 6 licensed crowdfunding operators in Malaysia and agencies involved in this are MDEC and MAGIC. MDEC and MAGIC and the 6 licensed crowdfunding companies will be approached to get the list of respondents. The appropriate sample size will be decided based on statistical recommendations, although a minimum of 100 responses is expected. As the research questions in this study pertain to crowdfunding supporters, they form the unit of analysis. Past literature will be referred to and small group of around 5 respondents will first be interviewed in order to understand the issues properly to develop the questionnaire. The developed questionnaire will be pilottested to confirm the validity of the questionnaire. Data collected will be entered and analyzed using structural equation modelling so that the relationships can be evaluated.

\section{Conclusion}

Early-stage entrepreneurs find it difficult to obtain funding for their businesses which are considered risky and their ideas being too innovative and complex. They are also unable to fulfill most of the requirements imposed by financiers. However, with the increasing number of web-based platforms, entrepreneurs are able to reach investors on a wider scale and crowdfunding is one of the new major sources of financing. However, being a new system which is online, there are certain risks associated with crowdfunding. Aside from this, the crowdfunding phenomenon needs to be sustainable in order to grow and benefit more entrepreneurs. The success of the phenomenon depends on the supporters of the funds. It is therefore important to study the decision making process and perception of risk of these crowdfunders (or 
supporters).

The results from this study are expected to influence government policy with regards to the alternative avenues for financing available, i.e. crowdfunding, to entrepreneurs and the provision of incentives to encourage supporters of projects to participate in crowdfunding activity for the success of entrepreneurial ventures in Malaysia, thus leading to the growth of the country. By understanding the psychology of the supporters, further steps can be taken to strengthen the regulations pertaining to crowdfunding to enable increased trust and participation in this growing industry. Results from this research is expected to benefit the crowdfunding community as well. It will provide insight into the decision making process of the project supporters providing project creators the knowledge to allow them to redesign their projects to successfully attract funding for their projects. Also, crowdfunding operators can redesign and refine their platforms to improve user interface and to better recruit and sustain participation in the crowdfunding community. Therefore, the increase in successful projects will result in a spur in entrepreneurial efforts and increased employment opportunity. Finally, this study would help both policy-makers and educators to identify non-traditional sources of financing for entrepreneurs and its viability. It is also hoped that the identification of various issues related to 'crowdfunder' psychology can help improve further the crowdfunding industry allowing it to grow so that entrepreneurs can have improved access to finance and hence, improve their chances of business survival and result in increased growth.

\section{Acknowledgement}

This research work is supported by the Fundamental Research Grant Scheme (FRGS) Cycle 1/2017 by the Malaysian Ministry of Higher Education.

\section{References}

Agrawal, A., Catalini, C., \& Goldfarb, A. (2015). Crowdfunding: Geography, social networks, and the timing of investment decision, Journal of Economics \& Management Strategy, Vol. 24 No. 2, pp. 253-274.

Asian Institute of Finance (2017). Crowdfunding Malaysia's Sharing Economy: Alternative Financing for Micro, Small and Medium Enterprises, Kuala Lumpur, Malaysia.

Belleflame, P., Lambert, T. \& Schwienbacher, A. (2010). Crowdfunding: An Industrial Organization Perspective. Prepared for the workshop Digital Business Models: Understanding Strategies', held in Paris on June. pp. 25-26.

Belleflame, P., Lambert, T. \& Schwienbacher, A. (2012). Crowdfunding: tapping the right crowd, Louvain-laNeuve, Belgium: Center for Operations Research and Econometrics.

Bettman, J. R. (1979). An information processing theory of consumer choice, Journal of Marketing, Vol. 43 No. 3 , pp. 124-126.

Blackwell, R. D., Miniard, P. W., \& Engel, J. F. (2001). Consumer behavior 9th. South-Western Thomas Learning. Mason, $\mathrm{OH}$.

Holbrook, M. B. (1996). Special Session Summary. Customer Value-A Framework for Analysis and Research, Advances in Consumer Research, Vol. 23 No. 2, pp. 138-142.

Kotha, R., \& George, G. (2012). Friends, family, or fools: Entrepreneur experience and its implications for equity distribution and resource mobilization, Journal of Business Venturing, Vol 27 No. 5, pp. 525-543.

Kraut, R. \& Resnick, P. (2012). Building Successful Online Communities: Evidence-Based Social Design, Cambridge: MIT Press.

Kuppuswamy, V., \& Bayus, B. L. (2015). Crowdfunding creative ideas: The dynamics of project backers in Kickstarter. UNC Kenan-Flagler Research Paper, (2013-15).

Lin, M., Prabhala, N. R., \& Viswanathan, S. (2013). Judging borrowers by the company they keep: friendship networks and information asymmetry in online peer-to-peer lending, Management Science, Vol. 59 No. 1, pp. 17-35.

Mollick, E. (2014). The dynamics of crowdfunding: An exploratory study, Journal of Business Venturing, Vol. 29 
No. 1, pp. 1-16.

Moysidou, K. and Spaeth, S. (2016). Cognition, emotion and perceived values in crowdfunding decision making, working paper, University of Hamburg.

Roig, J. C. F., Garcia, J. S., Tena, M. A. M., \& Monzonis, J. L. (2006). Customer perceived value in banking services. International Journal of Bank Marketing, Vol. 24 No. 5, pp. 266-283.

Schwienbacher, A. \& Larralde, B. (2012). Crowdfunding of Small Entrepreneurial Ventures. In Handbook of Entrepreneurial Finance. Oxford University Press.

Sheth, J. N., Newman, B. I., \& Gross, B. L. (1991). Why we buy what we buy: a theory of consumption values, Journal of Business Research, Vol. 22 No. 2, pp. 159-170.

Soete, B., \& Stephan, A. (2004). Introduction: Entrepreneurship, Innovation, and Growth, Industry and Innovation, Vol. 11 No. 3, pp. 161-165.

Turan, S. (2015). Financial Innovation - Crowdfunding: Friend or Foe? Procedia - Procedia Social and Behavioral Sciences, Vol. 195 No. 3, pp. 353-362.

Venkatachalam, V. B. \& Waqif, A. (2005). Outlook on Integrating Entrepreneurship in Management Education in India. Decision, Vol. 32 No. 2, pp. 57-71.

Verhaert, G. A., \& Van den Poel, D. (2012). The role of seed money and threshold size in optimizing fundraising campaigns: Past behavior matters! Expert Systems with Applications, Vol. 39 No. 18, pp. 13075-13084. Xu, A., Yang, X., Rao, H., Fu, W.-T., Huang, S.-W., \& Bailey, B. P. (2014). Show me the money!: An analysis of project updates during crowdfunding campaigns. In Proceedings of the SIGCHI Conference 